\title{
Composite Ferroelectric Coatings Based on a Heat-Resistant Polybenzoxazole Polymer Matrix
}

\author{
Nikolay Mukhin ${ }^{1,2, * \mathbb{D}}$, Irina Sokolova ${ }^{1} \mathbb{D}$, Dmitry Chigirev ${ }^{1}$, Lyudmila Rudaja ${ }^{3}$, \\ Galina Lebedeva ${ }^{4}$, Rene Kastro ${ }^{5}$, Maxim Bol'shakov ${ }^{4}$, Marc-Peter Schmidt ${ }^{2,6}$ and \\ Soeren Hirsch ${ }^{6}$ \\ 1 Saint Petersburg, Electrotechnical University “LETI”, 197376 Saint Petersburg, Russia; \\ imsokolova@mail.ru (I.S.); dachigirev@mail.ru (D.C.) \\ 2 Otto von Guericke University of Magdeburg, Magdeburg, 39106, Germany; schmmarc@th-brandenburg.de \\ 3 Saint Petersburg State Institute of Technology, Saint Petersburg, 190013, Russia; 9241890@mail.ru \\ 4 Institute of Macromolecular Compounds, Russian Academy of Sciences, Saint Petersburg, 199004, Russia; \\ lebedeva_gk@bk.ru (G.L.); bolshmax@rambler.ru (M.B.) \\ 5 Herzen State Pedagogical University of Russia, Saint Petersburg, 191186, Russia; recastro@mail.ru \\ 6 Department of Engineering, University of Applied Sciences Brandenburg, Magdeburger Str. 50, \\ 14770 Brandenburg an der Havel, Germany; soeren.hirsch@th-brandenburg.de \\ * Correspondence: mukhin.nikolay.v@gmail.com or mukhin.nikolay@ovgu.de
}

Received: 1 February 2020; Accepted: 16 March 2020; Published: 19 March 2020

\begin{abstract}
The polycondensation of 5,5-methylene bis(2-aminophenol) and the mixture of diamines 5,5-methylene bis(2-aminophenol) and 4,4-(hexafluoroisopropylidene)dianiline (molar ratio 0.8:0.2) with isophthaloyl dichloride was used to synthesize a new heat resistant binder of the composites for microelectronics: poly(o-hydroxyamide) (POA) and poly(amido-o-hydroxy amide) (POA-F). The thermal stability of synthesized polymer coatings, as well as based on them photosensitive compositions with a naphthoquinondiazide photosensitive component were studied in the temperature range from 100 to $500{ }^{\circ} \mathrm{C}$. Ferroelectric composites with nanodispersed lead titanate zirconate powder filler were formed based on these polymer matrices. By manipulating the conditions of the polymer formation, we obtained matrices with different stiffnesses, which reflected on the properties of the composite. The electrophysical parameters of the synthesized polymer and ferroelectric composite coatings were measured in the frequency range from $0.1 \mathrm{~Hz}$ to $1.5 \mathrm{GHz}$ and the temperature range from 0 to $300^{\circ} \mathrm{C}$. The frequency and temperature stability of the dielectric constant of ferroelectric composite coatings up to $10 \mathrm{MHz}$ and $300{ }^{\circ} \mathrm{C}$, respectively, are noted. The influence of the composition and structure of the polymer matrix and the grain/matrix interfaces on the thermal stability of the dielectric parameters of composite films is estimated. The shift of the phase transition region toward higher temperatures in the composite structure, as well as the sufficient rigidity of the poly(benzoxazole) matrix, provide high temperature and frequency stability of the dielectric constant of the studied composites.
\end{abstract}

Keywords: lead zirconate titanate; poly(o-hydroxy amide); 4,4-(hexafluoroisopropylidene) dianiline; 5,5-methylene bis(2-aminophenol); poly(o-hydroxyamide); composite ferroelectric coatings; thermal stability of dielectric properties

\section{Introduction}

The demands of modern electronics cannot be provided by classical materials and need new artificial materials with advanced functionality. One of the constructive approaches to solving this problem is the development of organic-inorganic composites. Properties of these composites are 
not a simple combination of those of the initial components; the composites may also acquire some additional functionalities that are provided by the processes occurring at the polymer/filler interface or at the interface between film coating and a substrate.

The most promising directions include preparation of composites with enhanced dielectric permittivity, relatively low dielectric losses, and high thermal stability of dielectric parameters.

The search for new polymer-based film composites with ferroelectric fillers and study of their properties remains an actual trend due to widening range of practical applications of these materials in various engineering areas (radioelectronics, optoelectronics, acoustic electronics, non-linear optics [1-4]).

The mainly used ferroelectric fillers are nanodispersed $\mathrm{BaTiO}_{3}[5-14]$ and nanodispersed powders of solid solutions of lead titanate zirconate (PZT) ferroelectric ceramics [13,15-17].

Properties of a polymer-based nanocomposite strongly depend not only on compositions of a filler and a matrix material, but also on the concentration of introduced filler, size of nanodispersed filler grains [12,18], degree of possible aggregation of nanodispersed filler, the nature of interactions occurring at the polymer matrix/filler interface [8,19-23], and degree of homogeneous distribution of a filler inside a matrix. Due to all these factors, it is possible to control properties of the prepared composites by varying some above-mentioned parameters.

In the development of film capacitors, including built-in capacitors for integrated circuits [16,24-26], the main goal is to obtain heat resistant composite film dielectrics (ferroelectric/polymer) with thermally stable enhanced values of dielectric permittivity $\left(\varepsilon^{\prime}\right)$ and reduced dielectric loss tangent $(\tan \delta)$. However, there is a contradiction between striving for increase in $\varepsilon^{\prime}$ (due to rise in filler amount) and the corresponding increase in losses in a dielectric composite. For instance, a number of studies of ferroelectric/polymer composites containing $\mathrm{BaTiO}_{3}$ as a ferroelectric component $[5,18,27-31]$ demonstrated that the achieved values of dielectric permittivity $\varepsilon^{\prime}$ in these composites range from 40 to 200 (depending on preparation technique and ferroelectric filler concentration). The values of filler load did not exceed $30 \mathrm{vol} . \%$. The dielectric loss tangent values lie in the range from 0.04 to 0.08 . Upon increase in the loaded amount of ferroelectric filler up to $40-45 \mathrm{vol} . \%$, the $\varepsilon^{\prime}$ value reaches 400 , although the $\tan \delta$ value, as expected, increases and exceeds 0.1 , and more.

The use of polymeric dielectric matrix that possesses enhanced electrical insulation properties is a reason for increasing electric strength of the composite films. The polymer matrix is also responsible for heat resistance of composite coating, for degree of adhesion to substrates of various chemical natures, and formation of the interface between polymer matrix and filler grains.

In the current work, with the purpose of enhancing dielectric parameters of ferroelectric/polymer film composites, we used polymer matrices such as poly(benzoxazoles) (PBO $[15,32,33]$ and PBO-F), obtained by a heat treatment of cyclodehydrationofpoly(o-hydroxyamides) (POA and POA-F). After thermal treatment (which causes chemical reaction of cyclodehydration), POA is transformed into highly hydrophobic poly(benzoxazole), $\mathrm{PBO}$. $\mathrm{PBO}$ possesses high heat resistance (up to $400^{\circ} \mathrm{C}$ ), high chemical stability and low water absorbing capacity. Due to these properties, this polymer is used in formation of protective coatings in various large scale integrated circuits and very large scale integrated circuits and other electronic devices [33].

The choice of lead titanate zirconate (PZT) powder as a ferroelectric filler is due to the unique properties of the PZT material as well as our previous experience in the formation of PZT films $[34,35]$ and MEMS devices based on it [36,37]. We also examined phenomena at the interfaces of PZT with other layers (e.g., $\mathrm{PZT} / \mathrm{PbO}[38]$ and $\mathrm{PZT} / \mathrm{CuO}[39,40]$ interfaces). In these previous works, we studied effects on phase interfaces and grain boundaries of PZT. On the other hand, the PZT system assumes a significant variation in the properties depending on the composition of $\mathrm{Zr} / \mathrm{Ti}$ or non-stoichiometry according to $\mathrm{Pb}$, including different impurities. That is, the wide variability of the PZT system, which allows in the future to play with the PZT composition and properties over a wide range and, as a consequence, the properties of the composite films. 
The purpose of the current work is to reveal the influence of the structure of the polymer matrix, the degree of loading of the filler, and the composite heat treatment temperature on the frequency and temperature stability of its electrophysical parameters. In accordance with this goal, we carried out more variable technological modes and used more initial components for matrix preparation: POA, POA-F, and photosensitive components. By manipulating the conditions of the polymer formation, we obtained matrices with different stiffnesses, which reflected on the properties of the composite. The important task was to study the problem of heat resistance in more detail. The heat resistance of the polymer matrix characterizes the ability of the polymer to break when heated. Therefore, increasing the heat resistance of the polymer matrix (that means a longer preservation of the composition and structure of the polymer when heated) is one of the factors contributing to the creation of a high-temperature thermostable dielectric. In this regard, an assessment was made of the heat resistance of synthesized polymer dielectrics, as well as photoresist compositions based on them.

\section{Materials and Methods}

\subsection{The Methods of Producing of PBO and PBO-F Polymer Matrices and Photoresists Based on Them}

The POA was selected as a basis for development of the polymer series. Synthesis of POA and POA-F was carried out using the polycondensation of 5,5-methylenebis(2-aminophenol), the mixture of diamines 5,5-methylenebis(2-aminophenol) and 4,4-(hexafluoroisopropylidene)dianiline (molar ratio 0.8:0.2) with isophthaloyl dichloride. After thermal treatment (which causes chemical reaction of cyclodehydration), POA is transformed into highly hydrophobic poly(benzoxazole), PBO. Thermal treatment of POA coating in accordance with the stepwise scheme $\left(150^{\circ} \mathrm{C}(15 \mathrm{~min}), 200^{\circ} \mathrm{C}(15 \mathrm{~min})\right.$, $250{ }^{\circ} \mathrm{C}(15 \mathrm{~min}), 300{ }^{\circ} \mathrm{C}(30 \mathrm{~min}), 350^{\circ} \mathrm{C}(15-30 \mathrm{~min})$ ) leads to polymer shrinkage (coating thickness decreases by $30 \%$ ). At the same time, degree of polyheterocyclization reaches $98 \%-99 \%$.

The prepared PBO polymer films had the following electrophysical parameters: volume resistivity is $10^{13} \mathrm{Ohm} \cdot \mathrm{m}$; breakdown voltage per unit of film thickness is not less than $300 \mathrm{~V} / \mu \mathrm{m}$ (when the layer thickness is higher than $2 \mu \mathrm{m}$ ). Dielectric permittivity and dielectric loss tangent at $10^{6} \mathrm{~Hz}$ vary from 3.5 to 4.5 and from 0.002 to 0.02 , respectively, depending on the final heat treatment temperature. Introducing fluorine into a macromolecule leads to its heat resistance increase, enhancement of dielectric parameters of polymer matrixes, and thus provides the possibility of extending areas of application of these fluorine-containing materials [41,42].

Isophthaloyl dichloride (IPC) (Sigma Aldrich, CAS 99-63-8) and 4,4-(hexafluoroisopropylidene) dianiline 98\% (Acros CAS 1095-78-9, New Jersy, NJ, USA) were used without preliminary purification. 2-(Chloromethyl)oxirane 98 \% (Panreac Quimica S.L.U, CAS 106-89-8, Barcelona, Spain) was distilled before use. 5,5-Methylene bis(2-aminophenol) was prepared according to the technique described in [32]. Synthesis conditions of POA-F were similar to those used for the preparation of POA-Si [43].

Photosensitive composites based on all synthesized polymers were prepared by mixing of reaction solution of polymeric binder with solution of Posylux 2402 in DMAA; the mass ratio between components was 5:1 (calculated for dry samples). The photosensitive component Posylux 2402 (FRAST-M, Moscow, Russia) was used without preliminary cleaning.

Heat resistance of films was estimated from mass losses of polymer films or photoresist films cast from reaction solution of polymers onto $\mathrm{Si}$ substrates; thermal treatment was conducted stepwise up to $500{ }^{\circ} \mathrm{C}$ at $50^{\circ} \mathrm{C}$ intervals, samples were exposed for $15 \mathrm{~min}$ at each temperature.

\subsection{The Methods of Ferroelectric/Polymer Composite Films Formation}

The film composites were obtained on the basis of the prepared polymers (as matrices) and included nanodispersed powder of solid solution of ferroelectric $\mathrm{Pb}_{0.81} \mathrm{Sr}_{0.04} \cdot \mathrm{Na}_{0.075} \mathrm{Bi}_{0.075}\left(\mathrm{Zr}_{0.58} \mathrm{Ti}_{0.42}\right) \mathrm{O}_{3}$ as a filler. The Curie temperature of a bulk ceramic sample is $240{ }^{\circ} \mathrm{C}$, the dielectric constant at room temperature is $2250 \pm 560, \tan \delta$ is around 0.019 . Here, $\mathrm{Na}$ and $\mathrm{Bi}$ are the most significant dopants in PZT. Often in literature [44,45] such compositions are abbreviated as PZTNB-1. 
To form a suspension of a composite with the PZTNB-1 ferroelectric filler, we used a diluted polymer solution of POA (or POA-F) after the completion of polycondensation. The manufacturing process of the initial suspension includes the following operations: mixing a specific portion of PZTNB-1 with a solvent (dimethylacetamide); thoroughly stirring up the suspension; further settling it for 3-5 min; separation of the upper layer with agitated particles from the sediment by decanting; subsequent mixing at room temperature of a drained suspension of the filler in dimethylacetamide with a weighed portion of the POA polymer reaction solution. A feature of the developed technology is that the ultrasonic dispersion of the ferroelectric filler powder was carried out directly in the polymer solution

In order to increase the composite loading degree, the method of sedimentation (deposition) from a suspension of a ferroelectric filler in a polymer solution was chosen. Suspensions of the filler in the polymer solution, placed in a closed glass vessel, were pre-processed using ultrasonic method to disperse the filler particles. After this, the substrates were loaded into special equipment, immersed at the bottom of the vessel with a suspension poured to a certain level, kept in it for a predetermined time, after which they were removed and dried. The deposition rate of the filler particles, and therefore the dependence of the thickness of the deposited ferroelectric filler layer on time, depends on many factors: the level of dispersion of the filler, the viscosity of the suspension, the height of the column of suspension above the substrate, the degree of decantation of the suspension, and the time of deposition. When fixing these factors, a proportional relationship is established between the deposition time, the composite film thickness and the composite loading degree. In the experiments, the viscosity of the suspension ( $6 \%$ and $12 \%$ polymer solution), the deposition time (in the range from 5 to $70 \mathrm{~min}$ ), the duration of decantation ( $30 \mathrm{~min}, 24 \mathrm{~h}, 9$ days, 20 days) were varied.

The key points of the technological procedure used for obtaining composite coatings:

(1) Mixing of components (POA solution in DMAA and ferroelectric powder filler) at room temperature without preliminary dispersion of filler particles;

(2) Ultrasound dispersion of the filler in polymer suspension that does not lead to destruction of the polymer, but provides formation of PZTNB-1 filler grains with sizes of 200-300 nm;

(3) Formation of composite coating on a substrate by sedimentation;

(4) Removal of excess polymer layer from the precipitated composite layer;

(5) Drying at $100^{\circ} \mathrm{C}$ for $1 \mathrm{~h}$;

(6) Thermal treatment of coatings: for polymer coatings: from $150{ }^{\circ} \mathrm{C}$ to $350{ }^{\circ} \mathrm{C}$ at $50^{\circ}$ intervals and for composite coatings: from $150^{\circ} \mathrm{C}$ to $300^{\circ} \mathrm{C}$. Heating rate was $10^{\circ} \mathrm{C} / \mathrm{min}$; after annealing, the samples cooled down slowly in the oven.

Heat treatment of polymeric, photoresist and composite coatings cast onto substrates was carried out in air in SUOL-0.25.1/12.5-I1 muffle furnace.

Ultrasound dispersion of ferroelectric powder was carried out in the solution of pre-polymer with the aid of an IL10-0.63 ultrasound generator (output power $630 \mathrm{~W}$ ) equipped with a PMS-O.63/22 magnetostrictive transducer (St. Petersburg, Russia). Its resonance frequency is $22,000 \mathrm{~Hz}$. Dispersion time was $60 \mathrm{~min}$.

Ultrasound treatment did not cause destruction of the polymer (IR spectra of the POA films cast before and after ultrasound dispersion were similar). Due to higher viscosity of the polymer suspension as compared to that of the filler suspension, aggregation of filler particles is considerably suppressed, and suspension properties become more stable in storage.

After removing the substrates, in order to obtain a higher degree of loading of the PZTNB-1/polymer composite coatings, it was necessary to carry out an additional procedure for removing excess polymer that protruded above the surface of the filler layer, forming a kind of layered structure. The reason for this phenomenon is the large surface tension of the polymer. The formation of a layered polymer/composite structure at this stage of operation is undesirable, since in this case the contribution of the ferroelectric component to the electrophysical characteristics is significantly reduced. Excess polymer was removed 
from the composite surface either manually using a porous material or using centrifugation at low centrifuge rotation speeds.

Preparation of samples for electrophysical studies. In order to obtain capacitor structures, lower platinum electrodes ( $80 \mathrm{~nm}$ thick) were deposited onto single-crystal silicon plate by ion plasma spraying; substrate temperature was $450{ }^{\circ} \mathrm{C}$. After formation of dielectric coating on substrate surface, its drying and thermal treatment, the system of higher electrodes (100 nm thick) was deposited through a shadow mask by ion plasma spraying. Dimensions of higher electrodes varied from 1 $\mathrm{mm}^{2}$ to $20 \mathrm{~mm}^{2}$. In order to increase filler load, we obtained composite coatings by sedimentation (deposition) from suspension of ferroelectric nanodispersed filler in the polymer solution. A peculiarity of this preparation method is that load of ferroelectric filler in the composite increases with increasing precipitation time and, correspondingly, with increase in coating thickness. Thickness of composite coatings was varied from 3 to $100 \mu \mathrm{m}$.

\subsection{Measurements of Electrophysical Parameters}

Dielectric parameters of the obtained capacitor structures (capacity and dielectric loss tangent) were measured at a frequency of $200 \mathrm{kHz}$ at room temperature using an E7-20 LCR meter (Minsk, Belarus). The corresponding values of dielectric permittivity and dielectric loss factor of coatings were calculated.

Dielectric spectra of polymeric and composite film coatings were registered in the frequency range of $0.1 \mathrm{~Hz}$ to $1.5 \mathrm{GHz}$ and in the temperature range 0 to $300{ }^{\circ} \mathrm{C}$ with the use of a «Novocontrol Concept 41» spectrometer (Novocontrol Technologies, Montabaur, Germany).

\section{Results and Discussion}

\subsection{The Study of PBO and PBO-F Polymer Matrices and Photoresists Based on Them}

Structural formulae of the synthesized polymers can be represented as follows. Figure 1a presents the scheme of transformation of the basic POA (I) upon thermal cyclodehydration and closure of benzoxazole ring in PBO. Figure $1 \mathrm{~b}$ gives structural formulae of the synthesized copolymer PBO-F, $\left(A_{m} B_{k}\right)_{n}$.

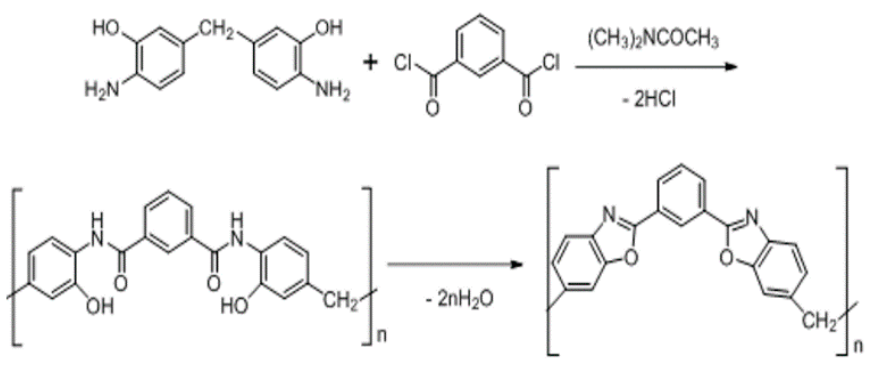

(a)
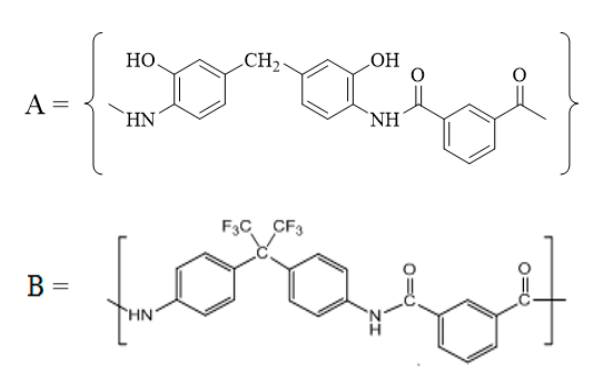

(b)

Figure 1. Scheme of transformation of poly(o-hydroxyamide) (POA) to poly(benzoxazoles) (PBO) during thermal cyclodehydration (a) and structural formulae of the synthesized copolymers (b).

During the heat treatment of POA, the heterocycle is formed, and the structure becomes more rigid. In the PBO-F copolymer, there are fewer units capable of forming such cycles during heat treatment, since the synthesis uses a mixture of two diamines, one of which does not contain a hydroxyl group in the ortho position, namely this group is involved in the formation of a new cycle during heat treatment. Accordingly, the structure in the PBO-F copolymer is more loose. The synthesized polymers are characterized by polydispersity (wide molecular weight distributions, MWD). In the base polymer, POA more than $40 \%$ are high molecular weight fractions with a molecular weight of more than 100.000 . The copolymer POA-F is characterized by a narrower MMP compared to POA. The main component is 
low molecular weight fractions with an $\mathrm{MM}<20.000$. The average polydispersity of POA-F is from 15.000 to 20.000 .

For a composite with a ferroelectric ceramic filler, the heat resistance of the composite coating is determined exclusively by the heat resistance of the polymer matrix. The thermal stability of the dielectric constant of the composite is determined by the set of thermal relaxation mechanisms inherent in both the ferroelectric grain and the polymer matrix. A significant contribution to the processes of temperature relaxation can be made by the interaction at the grain/matrix interface. The specificity of the studied composites is that during the formation of a rigid high molecular weight structure of the polymer matrix during heat treatment and crosslinking, the polymer coating shrinks by $20 \%-30 \%$, which can lead to mechanical stresses at the interface of the ferroelectric grain and, in turn, affect relaxation processes in ferroelectric.

The heat resistance of the polymer matrix characterizes the ability of the polymer to break when heated. Therefore, increasing the heat resistance of the polymer matrix (a longer preservation of the composition and structure of the polymer when heated) is one of the factors contributing to the creation of a high-temperature thermostable dielectric. In this regard, an estimation of the heat resistance of synthesized polymer dielectrics as well as photoresist compositions based on them was made. The results are shown in Figure 2a,b, respectively.

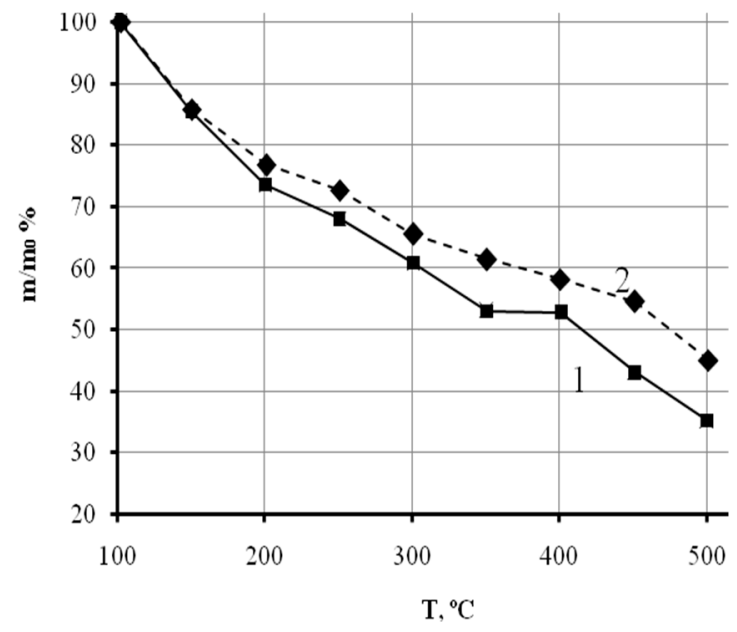

(a)

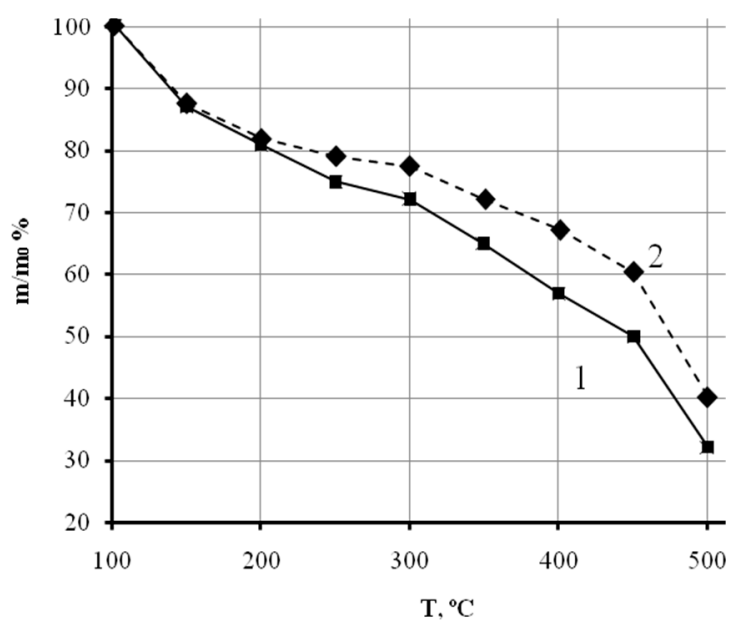

(b)

Figure 2. Mass losses of PBO (1) and PBO-F (2) polymer films formed from reaction solutions onto Si substrate (a) and mass losses of films of photoresist compositions based on PBO (1) and PBO-F (2) on an Si substrate (b). For the both cases the stepwise thermal treatment was up to $500{ }^{\circ} \mathrm{C}$ at $50{ }^{\circ} \mathrm{C}$ intervals and exposure for $15 \mathrm{~min}$ at each temperature.

In the given dependences of the heat resistance curves for both polymer films and films of photoresist compositions, several characteristic regions can be distinguished. Up to $250{ }^{\circ} \mathrm{C}$, mass loss is associated with the removal of the residual amount of solvent and the destruction of low molecular weight fractions. Polyheterocyclization with the formation of benzoxazole cycles occurs at 300-350 ${ }^{\circ} \mathrm{C}$ and is accompanied by a loss of $\sim 20 \%$ of the mass. When the temperature exceeds $400-450{ }^{\circ} \mathrm{C}$, the PBOs undergo thermodestruction.

Our studies confirmed the validity of the statement [41,42], that the introduction of fluorine-containing fragments increases the thermal stability of the polymer matrix. The presence of even $20 \%$ fluorine-containing units in the base matrix of PBO after cyclodehydration along with benzoxazole units leads to further rise in thermostability (approximately by $50-70^{\circ} \mathrm{C}$ ). The character of curves observed for photoresist films and for films formed from reactive polymer solutions is preserved. It can be stated that the polymer and photoresist films of the fluorine-containing copolymer PBO-F possess the highest heat resistance. 
Table 1 shows the values of the dielectric parameters of polymer coatings based on synthesized polymers, measured at a frequency of $200 \mathrm{kHz}$ at room temperature.

Table 1. The dielectric parameters of the film coatings based on PBO and PBO-F, measured at $200 \mathrm{kHz}$ at room temperature.

\begin{tabular}{ccc}
\hline Polymer Binder/Substrate & $\mathcal{\varepsilon}^{\prime}$ & $\tan \delta$ \\
\hline $\mathrm{PBO} / \mathrm{Si} / \mathrm{Pt}$ & 3.4 & 0.02 \\
$\mathrm{PBO}-\mathrm{F} / \mathrm{Si} / \mathrm{Pt}$ & 3.2 & 0.02 \\
\hline
\end{tabular}

Table 2 shows the dielectric parameters of the PBO film and photoresists based on it.

Table 2. The dielectric parameters of film coatings of the PBO polymer and photoresists based on it, measured at $1 \mathrm{MHz}$ at room temperature.

\begin{tabular}{ccc}
\hline Sample & $\mathcal{\varepsilon}^{\prime}$ & $\tan \delta$ \\
\hline PBO polymer & 3.4 & 0.028 \\
Photoresist 1 & 4.4 & 0.03 \\
Photoresist 2 & 4.2 & 0.03 \\
\hline
\end{tabular}

A photoresist is a mechanical mixture of the photosensitive component and the polymer matrix of the POA. An equimolar ratio of monomers (mixture diamines and isophthaloil dichloride) was taken at the synthesis of POA-F, but two methods of purification of one of the monomers, 5,5-methylenebis(2-aminophenol), were used and, as a result, two photoresists were obtained. The maximum temperature of heat treatment of coatings was $300^{\circ} \mathrm{C}$. For polymer and photoresist 1 , the monomer was purified by recrystallization from an aqueous solution of dimethylformamide, and for photoresist 2, the cleaning was carried out in two stages: first, before precipitation from the acid with ammonia, and then recrystallization from an aqueous solution of dimethylformamide. The effect of introducing the photosensitive component of the naphthoquinondiazide type on the dielectric characteristics of the polymer coating after thermal transformation of POA to PBO is illustrated by the data shown in Table 2 and Figure 3.

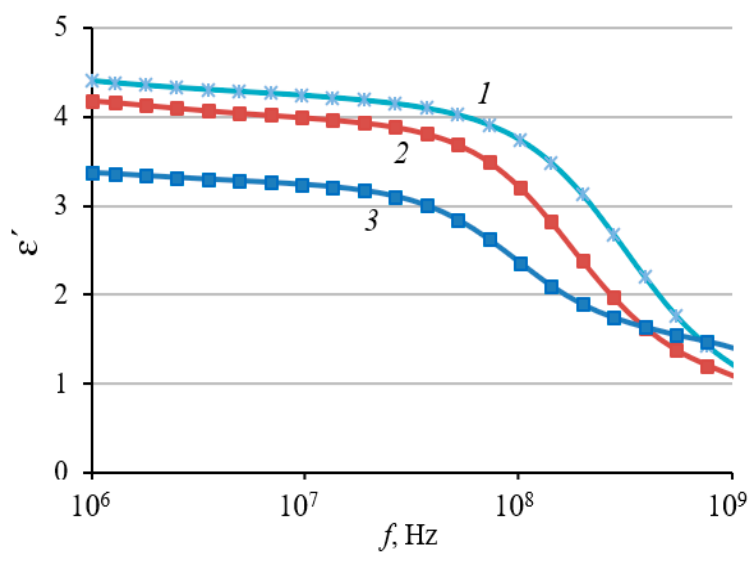

(a)

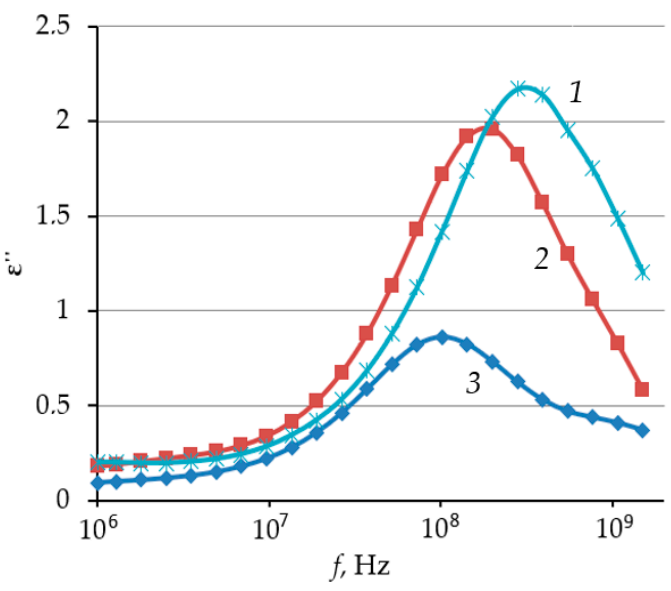

(b)

Figure 3. The dielectric spectra $\varepsilon^{\prime}(\mathbf{a})$ and $\varepsilon^{\prime \prime}(\mathbf{b})$, taken at room temperature, for a PBO based polymer film (3) and photoresist films $(1,2)$ obtained by introducing a photosensitive component into the PBO matrix. The 1st and the 2nd photoresists differ in the methods of purification of one of the monomers when producing POA. 
The PBO polymer manifests itself as a weakly polar insulator with low losses $(\tan \delta=0.02-0.03$ at $1 \mathrm{MHz}$ ), the main $\varepsilon^{\prime}$ dispersion is observed in the region from $10^{8}$ to $10^{9} \mathrm{~Hz}$. The introduction of a photosensitive component into the polymer matrix does not lead to a significant deterioration in its electrophysical parameters. The polarity of photoresists is slightly higher compared to the base polymer: $\varepsilon^{\prime}$ values and dielectric losses increase. The introduction of a photosensitive component helps to reduce the relaxation time of orientation processes in dielectrics, which leads to a shift in the maximum dielectric loss for photoresists to high frequencies. In the frequency range from $10^{6}$ to $10^{8}$ $\mathrm{Hz}$, both for the PBO polymer and for the photoresists based on it, a weak dispersion of $\varepsilon^{\prime}$ is observed.

\subsection{The Study of Ferroelectric/Polymer Composite Films}

The described polymer/ferroelectric composite technology was used to obtain such composites based on the light-sensitive composition PBO/Posylux 2402 with PZTNB-1 and a method for forming coatings of a given configuration and size was tested. Advantages of the polymer photosensitive matrix: high resolution, the possibility of manifestation in water-alkaline solvents, the ability to use standard lithographic equipment and high heat resistance (up to $400-450{ }^{\circ} \mathrm{C}$, as in the basic $\mathrm{PBO}$ ).

The obtained ferroelectric composite films are matrix mixtures, where the polymer forms a continuous medium (matrix), in which ferroelectric inclusions (without contact with each other) are discretely distributed. The two phases of this composite are unequal (they have significantly different $\varepsilon^{\prime}$ values). The properties of composites are largely determined by the nature of the distribution of the filler in the polymer matrix and the degree of dispersion of the filler, as well as the interaction on the interfaces. The higher the degree of dispersion and the stronger the intermolecular interaction at the interface, the greater the effect of the filler on the polymer composite properties. On the other hand, with a change in the degree of dispersion of ferroelectric fillers, a slight change in their intrinsic dielectric properties is noted. The change in the dielectric constant of the composites with a change in the size of the filler particles is explained by the existence of a surface layer of ferroelectric particles, the dielectric properties of which can noticeably differ from the properties in the particle volume due to its defectiveness $[34,38]$. The smaller the particle size, the smaller the particle volume/surface layer ratio and, therefore, the smaller its dielectric permittivity.

Owing to the application of the sedimentation method for the composite coatings formation, the $\varepsilon^{\prime}$ of films grows with increasing coating thickness, since the degree of ferroelectric filler loading of the composite increases (this is a feature of the used technology). Additionally, it is due to the reduction of relative contribution of the dielectric parameters of excess polymer layer on the surface of the deposited composite. The maximum values of dielectric permittivity equal to 185 and 430 in the experimental composite coatings corresponds to a degree of loading of a ferroelectric filler of 37 and 45 vol. \%, respectively.

Figure 4a shows that for the PZTNB-1/PBO composite coatings the thermostability of the dielectric constant is observed for different levels of filler loading (for different initial values of $\varepsilon^{\prime}$ ). The range of thermal stability of $\varepsilon^{\prime}$ depends primarily on the heat treatment temperature of the polymer composition. In Figure 4 a the samples 1 and 2 were treated at $250{ }^{\circ} \mathrm{C}$, the sample 3 was treated at $300{ }^{\circ} \mathrm{C}$. During heat treatment at 250 and $300{ }^{\circ} \mathrm{C}$, the degree of polymer heterocyclization is about 76 and $98 \%$, respectively. Coatings with a thickness from 7 to 15 microns were obtained from a suspension of 20-day exposure at a deposition time from 10 to $60 \mathrm{~min}$, respectively. The composite heat treatment temperatures for investigated composite films were: $250^{\circ} \mathrm{C}$ (curve 1), $240^{\circ} \mathrm{C}$ (curve 2 ) and $300^{\circ} \mathrm{C}$ (curve 3 ). The thickness of the polymer interlayers between the grains of the ferroelectric is more than $100 \mathrm{~nm}$ (Figure $4 \mathrm{~b}$ ). 


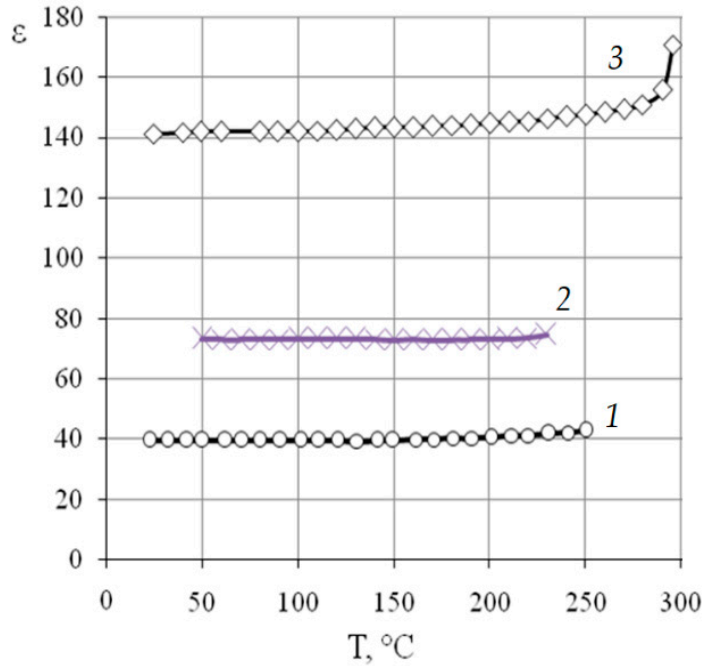

(a)

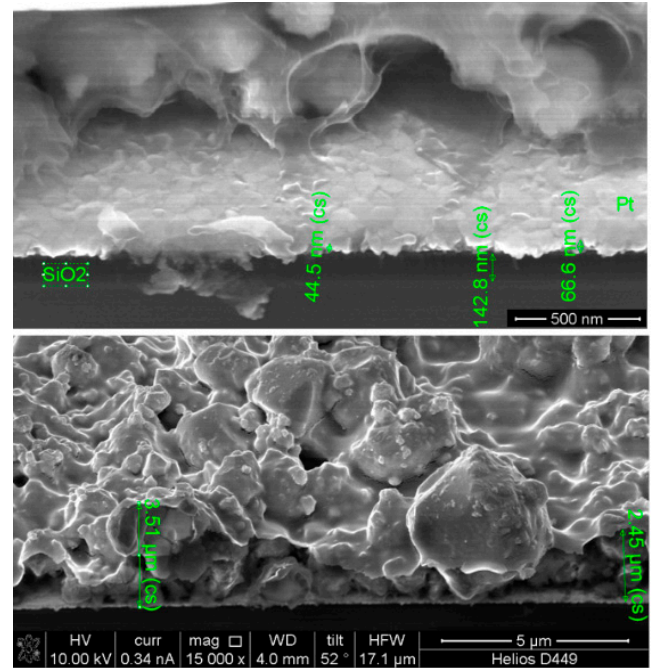

(b)

Figure 4. Temperature dependences of the dielectric constant for PZTNB-1/PBO composite films with different degrees of loading of the composite: around 30 (1), 32 (2), and 35 vol. \% (3), measured at a frequency of $200 \mathrm{kHz}$ at room temperature (a) after the heat treatment at 240 (2), 250 (1), and $300{ }^{\circ} \mathrm{C}(3)$, and the SEM images of obtained composite films (b).

Figure 5 shows the effect of the heat treatment temperature of PZTNB-1/PBO composite coatings on the dielectric spectra measured at room temperature. With an increase in the temperature of annealing of the composite from $250{ }^{\circ} \mathrm{C}$ to $300^{\circ} \mathrm{C}$, the structure of the polymer matrix changes due to the heterocyclization processes realized at elevated temperatures. In this case, the region of the main dielectric permittivity dispersion of the ferroelectric composite is shifted from $10^{5}-10^{6} \mathrm{~Hz}$ (Figure $5 \mathrm{a}$ ) to $10^{7}-10^{8} \mathrm{~Hz}$ (Figure $5 \mathrm{~b}$ ), and the ratio of the amplitudes of the low-frequency and high-frequency components of the spectrum tan $\delta$ also changes significantly.

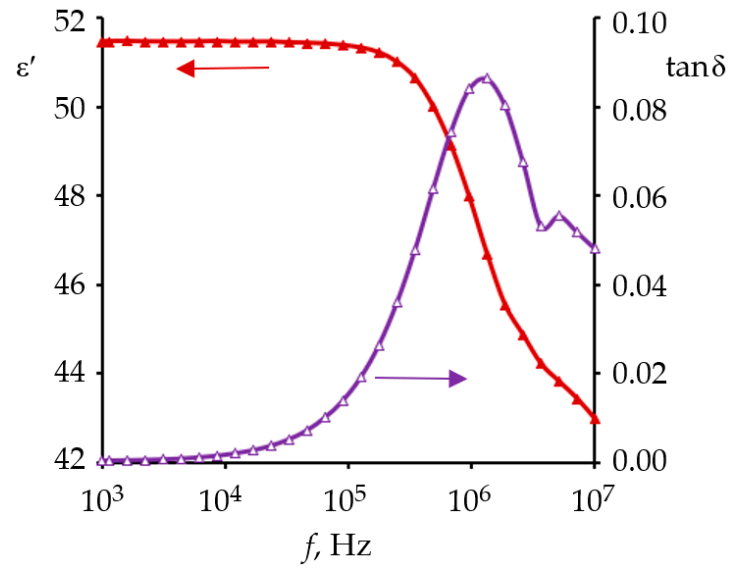

(a)

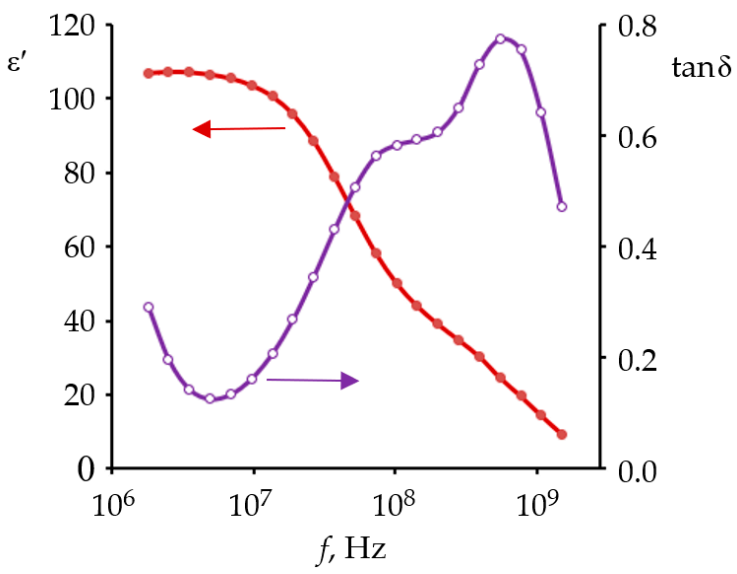

(b)

Figure 5. The frequency dependences of the dielectric constant $\varepsilon^{\prime}$ and tan $\delta$ measured at room temperature for composite coatings PZTNB-1/PBO, heat-treated at $250{ }^{\circ} \mathrm{C}(\mathbf{a})$ and $300{ }^{\circ} \mathrm{C}(\mathbf{b})$.

A possible increase in the mobility of the molecular units of the polymer with an increase in the measurement temperature practically does not lead to an increase in $\varepsilon^{\prime}$, which indicates a sufficient rigidity of the structure of the polymer matrix. The increase in $\varepsilon^{\prime}$ becomes noticeable only at temperatures close to the crosslinking temperature of the composite (Figure 6), and when the measurement temperature approaches the annealing temperature, losses also noticeably increase. 


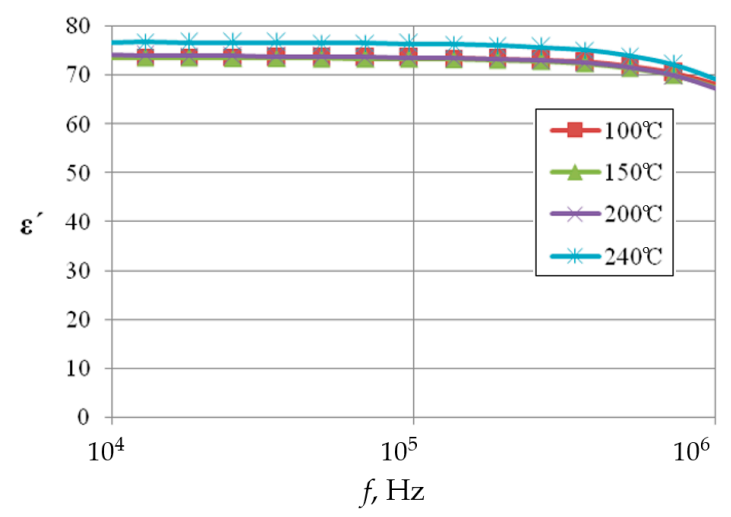

(a)

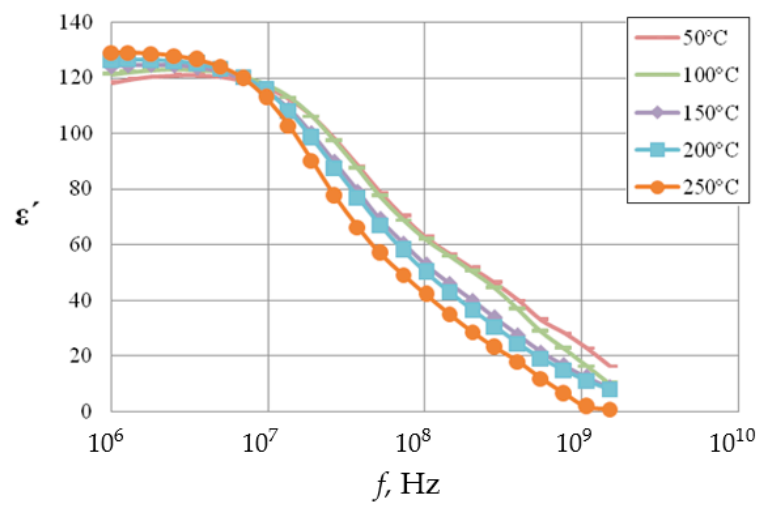

(b)

Figure 6. Frequency dependences of dielectric permittivity of composite coatings PZTNB-1/PBO, heat-treated at $250{ }^{\circ} \mathrm{C}(\mathbf{a})$ and $300{ }^{\circ} \mathrm{C}(\mathbf{b})$.

In addition, regardless of the temperature of the composite "crosslinking", there is an extremely weak dependence of $\varepsilon^{\prime}$ on the frequency before the onset of the dispersion region (variations in $\varepsilon^{\prime}$ do not exceed 5\%).

The dispersion of $\varepsilon^{\prime}$ in the frequency range from $10^{6}$ to $10^{9}$ is due to relaxation processes in the ferroelectric phase, both in the ferroelectric grain itself and at the ferroelectric/polymer interface. The structure of the tan $\delta$ peak in the region of the main dispersion of $\varepsilon^{\prime}$ indicates the complexity and heterogeneity of the characteristics of the bulk of the grain and its periphery. The specifics of the interaction of the polymer matrix and ferroelectric grains at the interface is determined, in particular, by the features of the composite technology, namely, significant polymer shrinkage up to $20 \%-30 \%$ during heat treatment (crosslinking). This leads to both the formation of a rather rigid structure of the polymer matrix and the appearance of mechanical stresses on the ferroelectric grain periphery. Such stresses change the parameters of relaxation processes in the interface region in comparison with the parameters of these processes in the bulk of the ferroelectric grain, which leads to the manifestation of two relaxation processes in the $\tan \delta$ spectrum.

The presence of a significant interaction at the ferroelectric/polymer interface is indicated, in particular, by the fact that the frequency dielectric spectra depend on the structural rearrangement of the polymer matrix with a change in the heat treatment temperature of the composite coating. With an increase in the heat treatment temperature to $300{ }^{\circ} \mathrm{C}$, the process of heterocyclization occurs in the polymer, the stiffness of the polymer matrix increases, which leads to a significant transformation of the peaks in the tan $\delta$ spectrum.

The observed transformation of the spectrum is caused, in particular, by an increase in mechanical stresses at the periphery of the ferroelectric grain, which slows down the slow relaxation processes at the grain/polymer interface and, as a result, the dispersion region shifts to a higher frequency region.

It should be especially noted that the Curie temperature range around $240{ }^{\circ} \mathrm{C}$ (characteristic of bulk ceramics PZTNB-1) does not appear in any way on these dependences.

The parameters of ferroelectric materials depend on the method of their preparation. In thin ferroelectric films (especially nanoscale ones), the physical properties differ from the properties of a bulk sample. This is due to the manifestation of size effects, the interaction of the film with adjacent layers and the substrate, as well as to an increased density of structural defects. Obviously, the characteristics of the composite with a connectivity of $0-3$, where the ferroelectric grains are distributed in the polymer matrix, will also differ from the characteristics of both bulk and film ferroelectric samples.

To identify these differences, we made a set of samples. A bulk sample of PZTNB-1 ceramics was made in the form of a disk obtained by pressing the initial ceramic powder. The disk thickness was $210 \mu \mathrm{m}$; Pt electrodes were deposited on both surfaces of the disk. Film PZTNB-1 samples 
with a thickness of $1.5 \mu \mathrm{m}$ were obtained by two stage technology (ex situ). At the first stage, a ferroelectric layer was formed by high-frequency reactive magnetron sputtering of a target from a PZTNB-1 piezoceramic with a stoichiometric composition. At the second stage, by conducting a heat treatment in air, the perovskite structure of the film ferroelectric layer was formed. To study the electrophysical properties of PZTNB-1 films with a thickness of $1.5 \mu \mathrm{m}$, the Si/Ti/Pt/PZTNB-1/Pt capacitor structures were formed. Film samples of the PZTNB-1/PBO and PZTNB-1/PBO-F composites with different ratio of ferroelectric filler were obtained using the proven technology on Si/Pt substrates. After annealing the composites, Pt electrodes were also deposited on their surface to form capacitor structures. The temperature dependences of $\varepsilon^{\prime}$ for the listed samples are shown in Figure 7.

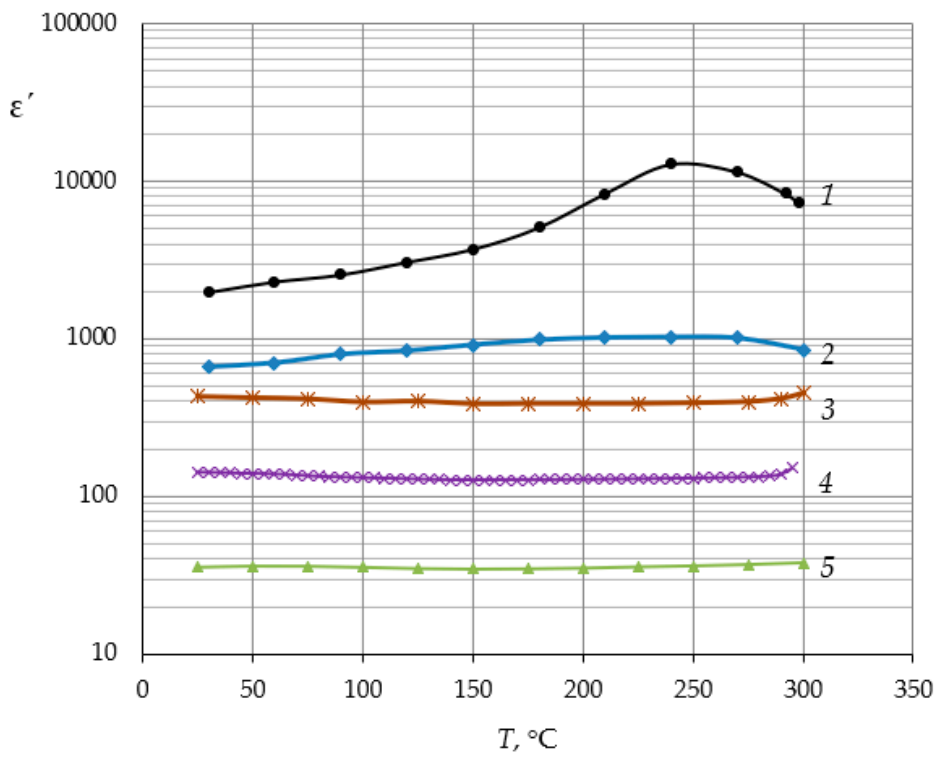

Figure 7. Comparison of temperature dependences of dielectric permittivity for a bulk ceramic sample PZTNB-1 (1); film sample PZTNB-1 on a Si-Pt substrate (2); film samples of a composite of nanosized PZTNB-1 powder in polymer PBO $(3,4)$ and PBO-F (5) matrices. The ratio of the PZTNB-1 filler was around 45 (3), 35 (4), and 30 (5) vol. \%.

The obtained results indicate that in the studied PZTNB-1/poly(benzoxazole) composite coatings there is a shift in the Curie temperature of the ferroelectric towards higher temperatures in comparison with the Curie temperature for bulk ceramic and film ferroelectric samples of the PZTNB-1. The shift takes place to values exceeding the temperature of heat treatment of the composite. Thus, the shift of the phase transition region toward higher temperatures in the composite structure, as well as the sufficient rigidity of the poly(benzoxazole) matrix, provide high temperature and frequency stability of the dielectric constant of the studied composites.

In fact, the heat resistance of the PZTNB-1/poly(benzoxazole) composites is determined primarily by the polymer matrix. We obtained composite films with different degrees of loading from 30 to $45 \%$, and their temperature behaviours were comparable. The influence of a ferroelectric filler is expressed both in the value of the dielectric constant and its frequency dispersion of composite films.

The potential applicability of the developed ferroelectric composites is seen in MEMS, microwave devices and high-voltage electronics, where heat-resistant and chemically-resistant dielectrics with high dielectric constant and electric strength are required.

\section{Conclusions}

In this work, we determined the heat resistance of polymer films, measured the dielectric parameters of the synthesized polymers, as well as photosensitive compositions with a naphthoquinondiazide component based on them. We carried out variable technological modes and 
used more initial components for matrix preparation: POA, POA-F, and photosensitive components. The PBO and PBO-F matrixes were obtained by a heat treatment of POA and POA-F. The variety of properties of polymer matrices is due to various conditions for their preparation and heat treatment, which we have changed over a wide range. Ferroelectric composites with nanodispersed lead titanate zirconate powder filler were formed based on these polymer matrices. By manipulating the conditions of the polymer formation, we obtained matrices with different stiffnesses, which reflected on the properties of the composite.

Dielectric spectroscopy was used to study the dielectric spectra of film coatings based on the PBO polymer and photosensitive compositions based on it. In the temperature range from 0 to 300 ${ }^{\circ} \mathrm{C}$, the dielectric spectra of film ferroelectric composites were studied for two variants of the polymer matrix: basic PBO and PBO-F copolymer. The influence of the composition and structure of the polymer matrix and the characteristics of the interaction at the ferroelectric grain/polymer matrix interface on the thermal stability of the dielectric parameters of composite films is analysed.

The PZTNB-1 grain sizes were 200-300 nm; the ratio of the PZTNB-1 filler to polymer matrix was changed from 30 to $45 \%$; effective dielectric constant of the composite was changed from 40 to 430 .

Our studies confirmed, that the introduction of fluorine-containing fragments increases the thermal stability of the polymer matrix. The presence of even $20 \%$ fluorine-containing units in the base matrix of PBO after cyclodehydration along with benzoxazole units leads to further rise in thermostability (approximately by $50-70{ }^{\circ} \mathrm{C}$ ). The polymer and photoresist films of the fluorine-containing copolymer PBO-F possess the highest heat resistance.

The complex structure of the high-frequency peak $\tan \delta$ in the region of the main $\varepsilon^{\prime}$ dispersion indicates the complexity and heterogeneity of the characteristics of the bulk of the grain and its periphery (interface). The specifics of the interaction of the polymer matrix and ferroelectric grains at the interface is determined, in our opinion, by the features of the technology for producing the composite, namely, significant polymer shrinkage up to $20 \%-30 \%$ during annealing (crosslinking). This leads both to the formation of a rather rigid structure of the polymer matrix and to the appearance of mechanical stresses on the ferroelectric grain periphery. Such stresses change the parameters of relaxation processes in the interface region compared with the parameters of these processes in the bulk of the grain, which leads to the manifestation of two relaxation processes in the high-frequency part of the spectrum $\tan \delta$. We assume that with an increase in the measurement temperature, the mobility of polymer chains increases. As a result, the stiffness of the polymer matrix decreases, the mobility of the ferroelectric domain walls at the grain boundary increases, and losses increase.

The shift of the phase transition region toward higher temperatures in the composite structure, as well as the sufficient rigidity of the poly(benzoxazole) matrix, provide high temperature and frequency stability of the dielectric constant of the studied composites.

The heat resistance of the PZTNB-1/PBO and PZTNB-1/PBO-F composites is determined primarily by the polymer matrix for loading rates from 30 to 45 percent in the temperature range from 0 to $300{ }^{\circ} \mathrm{C}$.

\section{Patents}

There are our previous patents related to the research. Rudaya, L.I.; Shamanin, V.V.; Lebedeva, G.K.; Sokolova, I.M.; Afanasjev, V.P.; Bol'shakov, M.N.; Marfichev, A.Y.; Chigirev, D.A. A method for producing a nanocomposite material for heat- and chemically resistant coatings and planar layers with high dielectric permittivity. RF Patent 2478663, 4 October 2013. Rudaja L. I., Shamanin V. V., Birjulin Ju. F., Terukov E. I., Klimova N. V. Tkachev A. G., Kurdybajlo D. S., Marfichev A. Ju. Method of producing heat-resistant material for protective coating. RF Patent 2373246, 11 January 2008. Rudaja L. I., Shamanin V. V., Lebedeva G. K., Marfichev A. Ju., Elokhin V. A., Gotlib V. A., Vladimirov F.L., Girin A.S. Laser sensitive polymer coating. RF Patent 2522604, 08 August 2012. Rudaja L. I., Shamanin V. V., Lebedeva G. K., Marfichev A. Ju., Elokhin V. A., Gotlib V. A., Vladimirov F.L., Girin A.S. Luminescent composite coatings. RF Patent 2505579, 08 August 2012. Zabello A.G., Kuzmov M.V., Rudaja L.I., 
Shamanin V.V., Lebedeva G.K., Bolshakov M.N. Gaseous medium capacitive moisture content sensor. RF Patent 2602489, 15 July 2015.

Author Contributions: Conceptualization, I.S. and L.R.; methodology, L.R. and G.L.; validation, L.R., G.L., and N.M.; investigation, R.K., D.C., and G.L.; resources, N.M., M.B., and S.H.; data curation, I.S., D.C., and N.M.; writing — original draft preparation, D.C.; writing-review and editing, N.M., M.-P.S., and I.S. All authors have read and agreed to the published version of the manuscript.

Funding: The work was supported by the Ministry of Science and Higher Education of the Russian Federation (state assignment 785.00.X6019).

Acknowledgments: The authors are grateful to Yuliya V. Shagayko, undergraduate student of Saint Petersburg State Institute of Technology (Technical University) for providing the data on thermostability of the fluorine-containing copolymer.

Conflicts of Interest: The authors declare no conflict of interest.

\section{References}

1. Barber, P.; Balasubramanian, S.; Anguchamy, Y.; Gong, S.; Wibowo, A.; Gao, H.; Ploehn, H.; Zur Loye, H.-C. Polymer Composite and Nanocomposite Dielectric Materials for Pulse Power Energy Storage. Materials (Basel) 2009, 2, 1697-1733. [CrossRef]

2. Singh, P.; Borkar, H.; Singh, B.P.; Singh, V.N.; Kumar, A. Ferroelectric polymer-ceramic composite thick films for energy storage applications. Aip Adv. 2014, 4, 87117. [CrossRef]

3. Tanaka, T. Dielectric nanocomposites with insulating properties. IEEE Trans. Dielect. Electr. Insul. 2005, 12, 914-928. [CrossRef]

4. Khan, M.N.; Jelani, N.; Li, C.; Khaliq, J. Flexible and low cost lead free composites with high dielectric constant. Ceram. Int. 2017, 43, 3923-3926. [CrossRef]

5. Srivastava, A.; Jana, K.K.; Maiti, P.; Kumar, D.; Parkash, O. Poly(vinylidene fluoride)/CaCu $3 \mathrm{Ti}_{4} \mathrm{O}_{12}$ and $\mathrm{La}$ doped $\mathrm{CaCu}_{3} \mathrm{Ti}_{4} \mathrm{O}_{12}$ composites with improved dielectric and mechanical properties. Mater. Res. Bull. 2015, 70, 735-742. [CrossRef]

6. Oseev, A.; Lucklum, R.; Zubtsov, M.; Schmidt, M.-P.; Mukhin, N.V.; Hirsch, S. SAW-Based Phononic Crystal Microfluidic Sensor-Microscale Realization of Velocimetry Approaches for Integrated Analytical Platform Applications. Sensors (Basel) 2017, 17. [CrossRef]

7. Singh, A.P.; Singh, Y.P. Dielectric behavior of $\mathrm{CaCu}_{3} \mathrm{Ti}_{4} \mathrm{O}_{12}$ : Poly Vinyl Chloride ceramic polymer composites at different temperature and frequencies. Mod. Electron. Mater. 2016, 2, 121-126. [CrossRef]

8. Wu, M.; Yuan, X.; Luo, H.; Chen, H.; Chen, C.; Zhou, K.; Zhang, D. Enhanced actuation performance of piezoelectric fiber composites induced by incorporated $\mathrm{BaTiO}_{3}$ nanoparticles in epoxy resin. Phys. Lett. A 2017, 381, 1641-1647. [CrossRef]

9. Kim, D.S.; Baek, C.; Ma, H.J.; Kim, D.K. Enhanced dielectric permittivity of $\mathrm{BaTiO}_{3} /$ epoxy resin composites by particle alignment. Ceram. Int. 2016, 42, 7141-7147. [CrossRef]

10. Adam, J.; Lehnert, T.; Klein, G.; McMeeking, R.M. Ferroelectric properties of composites containing $\mathrm{BaTiO}_{3}$ nanoparticles of various sizes. Nanotechnology 2014, 25, 65704. [CrossRef]

11. Pavlović, V.P.; Pavlović, V.B.; Vlahović, B.; Božanić, D.K.; Pajović, J.D.; Dojčilović, R.; Djoković, V. Structural properties of composites of polyvinylidene fluoride and mechanically activated $\mathrm{BaTiO}_{3}$ particles. Phys. Scr. 2013, T157, 14006. [CrossRef]

12. Robertson, J.; Hall, D.A. Nonlinear dielectric properties of particulate barium titanate-polymer composites. J. Phys. Condens. Matter 2008, 41, 115407. [CrossRef]

13. Tiwari, V.; Srivastava, G. Structural, dielectric and piezoelectric properties of 0-3 PZT/PVDF composites. Ceram. Int. 2015, 41, 8008-8013. [CrossRef]

14. He, D.; Wang, Y.; Chen, X.; Deng, Y. Core-shell structured $\mathrm{BaTiO}_{3} @ \mathrm{Al}_{2} \mathrm{O}_{3}$ nanoparticles in polymer composites for dielectric loss suppression and breakdown strength enhancement. Compos. Part A Appl. Sci. Manuf. 2017, 93, 137-143. [CrossRef]

15. Rudaya, L.I.; Shamanin, V.V.; Lebedeva, G.K.; Sokolova, I.M.; Afanasjev, V.P.; Bol'shakov, M.N.; Marfichev, A.Y.; Chigirev, D.A. A Method for Producing a Nanocomposite Material for Heat- and Chemically Resistant Coatings and Planar Layers with High Dielectric Permittivity. RF Patent 2478663, 4 October 2013. 
16. Lin, J.; Tong, P.; Zhang, K.; Ma, X.; Tong, H.; Guo, X.; Yang, C.; Wu, Y.; Wang, M.; Lin, S.; et al. The GaNMn 3 -Epoxy composites with tunable coefficient of thermal expansion and good dielectric performance. Compos. Sci. Technol. 2017, 146, 177-182. [CrossRef]

17. Mukhin, N.; Afanasjev, V.; Sokolova, I.; Chigirev, D.; Kastro, R.; Rudaja, L.; Lebedeva, G.; Oseev, A.; Tumarkin, A. Heat-Resistant Ferroelectric-Polymer Nanocomposite with High Dielectric Constant. Materials (Basel) 2018, 11, 1439. [CrossRef]

18. Weadon, T.L.; Evans, T.H.; Sabolsky, E.M. Ceramic-polymer capacitive sensors for tactile/force awareness in harsh environment robotic applications. Smart Mater. Struct. 2013, 22, 125017. [CrossRef]

19. Zhang, X.; Zhao, S.; Wang, F.; Ma, Y.; Wang, L.; Chen, D.; Zhao, C.; Yang, W. Improving dielectric properties of $\mathrm{BaTiO}_{3} /$ poly(vinylidene fluoride) composites by employing core-shell structured $\mathrm{BaTiO}_{3} @ \mathrm{Poly}\left(\right.$ methylmethacrylate) and $\mathrm{BaTiO}_{3} @$ Poly(trifluoroethyl methacrylate) nanoparticles. Appl. Surf. Sci. 2017, 403, 71-79. [CrossRef]

20. Dash, S.; Choudhary, R.N.P.; Goswami, M.N. Enhanced dielectric and ferroelectric properties of $\mathrm{PVDF}^{-\mathrm{BiFeO}_{3}}$ composites in 0-3 connectivity. J. Alloy Compd. 2017, 715, 29-36. [CrossRef]

21. Zhang, C.; Chi, Q.; Dong, J.; Cui, Y.; Wang, X.; Liu, L.; Lei, Q. Enhanced dielectric properties of poly(vinylidene fluoride) composites filled with nano iron oxide-deposited barium titanate hybrid particles. Sci. Rep. 2016, 6, 33508. [CrossRef]

22. Wan, Y.-J.; Zhu, P.-L.; Yu, S.-H.; Yang, W.-H.; Sun, R.; Wong, C.-P.; Liao, W.-H. Barium titanate coated and thermally reduced graphene oxide towards high dielectric constant and low loss of polymeric composites. Compos. Sci. Technol. 2017, 141, 48-55. [CrossRef]

23. Zhang, Q.; Gao, F.; Zhang, C.; Wang, L.; Wang, M.; Qin, M.; Hu, G.; Kong, J. Enhanced dielectric tunability of $\mathrm{Ba}_{0.6} \mathrm{Sr}_{0.4} \mathrm{TiO}_{3} / \mathrm{Poly}$ (vinylidene fluoride) composites via interface modification by silane coupling agent. Compos. Sci. Technol. 2016, 129, 93-100. [CrossRef]

24. Moharana, S.; Mahaling, R.N. Silver (Ag)-Graphene oxide (GO)-Poly (vinylidene fluoride-cohexafluoropropylene) (PVDF-HFP) nanostructured composites with high dielectric constant and low dielectric loss. Chem. Phys. Lett. 2017, 680, 31-36. [CrossRef]

25. Fang, M.; Wang, Z.; Li, H.; Wen, Y. Fabrication and dielectric properties of $\mathrm{Ba}\left(\mathrm{Fe}_{0.5} \mathrm{Nb}_{0.5}\right) \mathrm{O}_{3} /$ poly (vinylidene fluoride) composites. Ceram. Int. 2015, 41, S387-S392. [CrossRef]

26. Goyal, R.K.; Katkade, S.S.; Mule, D.M. Dielectric, mechanical and thermal properties of polymer $/ \mathrm{BaTiO}_{3}$ composites for embedded capacitor. Compos. Part B Eng. 2013, 44, 128-132. [CrossRef]

27. Fomin, A.A.; Steinhauer, A.B.; Rodionov, I.V.; Fomina, M.A.; Zakharevich, A.M.; Skaptsov, A.A.; Gribov, A.N.; Karsakova, Y.D. Properties of titanium dioxide coatings produced by induction-thermal oxidation of VT1-00 alloy. J. Frict. Wear 2014, 35, 32-39. [CrossRef]

28. Joseph, N.; Singh, S.K.; Sirugudu, R.K.; Murthy, V.R.K.; Ananthakumar, S.; Sebastian, M.T. Effect of silver incorporation into PVDF-barium titanate composites for EMI shielding applications. Mater. Res. Bull. 2013, 48, 1681-1687. [CrossRef]

29. Shin, S.-H.; Kim, Y.-H.; Jung, J.-Y.; Lee, M.H.; Nah, J. Solvent-assisted optimal $\mathrm{BaTiO}_{3}$ nanoparticles-polymer composite cluster formation for high performance piezoelectric nanogenerators. Nanotechnology 2014, 25, 485401. [CrossRef]

30. Moharana, S.; Mishra, M.K.; Chopkar, M.; Mahaling, R.N. Enhanced dielectric properties of surface hydroxylated bismuth ferrite-Poly (vinylidene fluoride-co-hexafluoropropylene) composites for energy storage devices. J. Sci. Adv. Mater. Devices 2016, 1, 461-467. [CrossRef]

31. Liu, L.; Lv, F.; Zhang, Y.; Li, P.; Tong, W.; Ding, L.; Zhang, G. Enhanced dielectric performance of polyimide composites with modified sandwich-like $\mathrm{SiO}_{2} @ G O$ hybrids. Compos. Part. A Appl. Sci. Manuf. 2017, 99, 41-47. [CrossRef]

32. Lebedeva, G.K.; Bazhenova, A.S.; Rudaya, L.I.; Gofman, I.V.; Marfichev, A.Y.; Bol'shakov, M.N.; Sokolova, I.M.; Chigirev, D.S.; Ramsh, S.M.; Shamanin, V.V. Highly heat-resistant poly(o-hydroxy amide) binders of polyfunctional composites for microelectronics. Russ. J. Appl. Chem. 2016, 89, 1647-1654. [CrossRef]

33. Afanasjev, V.; Bol'shakov, M.; Castro, R.; Lebedeva, G.; Marfichev, A.; Sokolova, I.; Rudaya, L.; Chigirev, D.; Shamanin, V. High heat stable poly(o-hydroxyamides) based polymers for polyfunctional composites in microelectronics. Bull. St. Petersburg State Technol. Univ. 2012, 16, 72-77. 
34. Afanas'ev, V.P.; Vorotilov, K.A.; Mukhin, N.V. Effect of the synthesis conditions on the properties of polycrystalline films of lead zirconate titanate of nonstoichiometric composition. Glass Phys. Chem. 2016, 42, 295-301. [CrossRef]

35. Agafonova, D.S.; Kozyrev, A.B.; Mukhin, N.V.; Red'ka, D.N.; Elanskaya, K.G.; Rudenko, M.V.; Oseev, A.; Hirsch, S. Impurity Phases in Polycrystalline Films of Ferroelectric Oxides of the Perovskite-Type on the Basis of $\mathrm{Bi}_{2} \mathrm{SrTa}_{2} \mathrm{O}_{9}$ and $\mathrm{Pb}(\mathrm{Zr}, \mathrm{Ti}) \mathrm{O}_{3}$. Glass Phys. Chem. 2018, 44, 15-20. [CrossRef]

36. Hirsch, S.; Doerner, S.; Schimpf, S.; Lucklum, R.; Hauptmann, P.; Schmidt, B. A new device with PZT ultrasonic transducers in MEMS technology. J. Phys. Conf. Ser. 2006, 34, 475-480. [CrossRef]

37. Schmidt, M.-P.; Oseev, A.; Engel, C.; Brose, A.; Aman, A.; Hirsch, S. A Novel Design and Fabrication of Multichannel Microfluidic Impedance Spectroscopy Sensor for Intensive Electromagnetic Environment Application. Procedia Eng. 2014, 87, 88-91. [CrossRef]

38. Mukhin, N.; Chigirev, D.; Bakhchova, L.; Tumarkin, A. Microstructure and Properties of PZT Films with Different PbO Content-Ionic Mechanism of Built-In Fields Formation. Materials (Basel) 2019, 12, 2926. [CrossRef]

39. Adilov, S.R.; Afanaciev, V.P.; Kashkul, I.N.; Kumekov, S.E.; Mukhin, N.V.; Terukov, E.I. Studying the composition and structure of films obtained by thermal oxidation of copper. Glass Phys. Chem. 2017, 43, 272-275. [CrossRef]

40. Kochunov, K.V.; Konoplev, G.A.; Mukhin, N.D.; Chigirev, D.A. Investigation of photoelectric properties of $\mathrm{CuO} / \mathrm{PZT}$ heterostructures in the visible and near IR regions. J. Phys. Conf. Ser. 2019, 1400, 66054. [CrossRef]

41. Tao, L.; Yang, H.; Liu, J.; Fan, L.; Yang, S. Synthesis of fluorinated polybenzoxazoles with low dielectric constants. J. Polym. Sci. A Polym. Chem. 2010, 48, 4668-4680. [CrossRef]

42. Banerjee, S. (Ed.) Handbook of Specialty Fluorinated Polymers: Preparation, Properties, and Applications; Elsevier: Amsterdam, The Netherlands, 2015; ISBN 9780323357920.

43. Rudaya, L.I.; Strelina, I.A.; Okatova, O.V.; Bezrukova, M.A.; Bol'shakov, M.N.; Marfichev, A.Y.; Lebedeva, G.K.; Ramsh, S.M. Heat-Resistant Polyfunctional Materials for Microelectronics: Hydrodynamic, Optical, and Conformational Properties of Si-Containing Poly(ortho-Hydroxy Amide). Russ. J. Appl. Chem. 2017, 90, 1771-1777. [CrossRef]

44. Galiyarova, N.M.; Bey, A.B.; Kuznetzov, E.A.; Korchhmariyuk, Y.I. Fractal Dimensionalities and Microstructure Parameters of Piezoceramic PZTNB-1. Ferroelectrics 2004, 307, 205-211. [CrossRef]

45. Lisnevskaya, I.V.; Bobrova, I.A.; Lupeiko, T.G. Comparison of the properties of PZTNB-1 + $\mathrm{Ni}_{0.9} \mathrm{Co}_{0.1} \mathrm{Cu}_{0.1} \mathrm{Fe}_{1.9} \mathrm{O}_{4}-\delta$ magnetoelectric composites manufactured from components synthesized by Sol-Gel processes. Russ. J. Inorg. Chem. 2012, 57, 84-89. [CrossRef] 